\title{
Technical Note: The effect of sensor resolution on the number of cloud-free observations from space
}

\author{
J. M. Krijger ${ }^{1}$, M. van Weele ${ }^{2}$, I. Aben ${ }^{1}$, and R. Frey ${ }^{3}$ \\ ${ }^{1}$ SRON, Netherlands Institute for Space Research, Sorbonnelaan 2, 3584 CA Utrecht, The Netherlands \\ ${ }^{2}$ KNMI, Royal Netherlands Meteorological Institute, De Bilt, The Netherlands \\ ${ }^{3}$ Cooperative Institute for Meteorological Satellite Studies, University of Wisconsin-Madison, Madison, WI, USA
}

Received: 23 January 2006 - Published in Atmos. Chem. Phys. Discuss.: 7 June 2006

Revised: 5 October 2006 - Accepted: 22 May 2007 - Published: 11 June 2007

\begin{abstract}
Air quality and surface emission inversions are likely to be focal points for future satellite missions on atmospheric composition. Most important for these applications is sensitivity to the atmospheric composition in the lowest few kilometers of the troposphere. Reduced sensitivity by clouds needs to be minimized. In this study we have quantified the increase in number of useful footprints, i.e. footprints which are sufficient cloud-free, as a function of sensor resolution (footprint area). High resolution $(1 \mathrm{~km} \times 1 \mathrm{~km})$ MODIS TERRA cloud mask observations are aggregated to lower resolutions. Statistics for different thresholds on cloudiness are applied. For each month in 2004 four days of MODIS data are analyzed. Globally the fraction of cloudfree observations drops from $16 \%$ at $100 \mathrm{~km}^{2}$ resolution to only $3 \%$ at $10000 \mathrm{~km}^{2}$ if not a single MODIS observation within a footprint is allowed to be cloudy. If up to $5 \%$ or $20 \%$ of a footprint is allowed to be cloudy, the fraction of cloudfree observations is $9 \%$ or $17 \%$, respectively, at $10000 \mathrm{~km}^{2}$ resolution. The probability of finding cloud-free observations for different sensor resolutions is also quantified as a function of geolocation and season, showing examples over Europe and northern South America (ITCZ).
\end{abstract}

\section{Introduction}

Satellite-based passive remote sensing is commonly used to derive global information about the composition of the Earth's atmosphere, e.g. in relation to the ozone layer, climate change or air quality. Information about the total column or even vertical profiles of different gases in the Earth atmosphere can be obtained by measuring the radiance (intensity) spectrum of sunlight reflected by the Earth's atmosphere and surface, since these spectra contain absorption

Correspondence to: J. M. Krijger

(krijger@sron.nl) bands of gases present in the atmosphere, such as ozone $\left(\mathrm{O}_{3}\right)$ and nitrogen dioxide $\left(\mathrm{NO}_{2}\right)$.

Satellite observations of trace gas columns can be seen as a projection or footprint on the Earth surface. A footprint covers an extended area over which the radiance is averaged. The presence of cloudiness within a footprint shields part of the area and strongly reduces sensitivity to the trace gases below the clouds. Cloudiness also affects the average reflected radiance. Because clouds are typically more reflective than the cloud-free atmosphere plus Earth's surface, the presence of even a small amount of cloudiness in the footprint drastically reduces the sensitivity to trace gases near the surface in the same footprint (Meirink et al., 2005). Therefore, trace gas observations in the troposphere should be minimised for their impact of cloudiness.

Smaller footprints will decrease the probability of finding clouds within the footprint, and increase the sensitivity to trace gas concentrations in the lowest atmospheric layers. The size of a footprint is determined by sensor resolution, which is limited by the instantaneous field-of-view (IFOV) or movement of the IFOV during a single measurement. An increase in sensor resolution decreases the size of the footprint and thus the number of cloud-contaminated footprints. In practice, limitations exist to the resolution related to, e.g., the integration time and required signal-to-noise.

In the ultra-violet (UV), visible (VIS) and near infra-red (NIR) wavelength range clouds effectively screen the lower part of the atmosphere. Because typically more than 90 percent of the total ozone column is situated above cloud top, corrections for cloudiness can be applied in the retrieval of a total ozone column (Koelemeijer and Stammes, 1999). However, for example, for the observation of pollutant concentration levels in the boundary layer and the derivation of pollutant sources and sinks at the Earth's surface using inverse modelling, the observations need to be close to cloud-free at the time of observation.

Published by Copernicus GmbH on behalf of the European Geosciences Union. 
The full potential of satellite instruments for air quality and other tropospheric applications has only recently been fully perceived and has followed the development of a new generation of solar-backscatter instruments with high spectral resolution with sensor resolutions that have been increasing from instrument to instrument. The GOME instrument launched on ERS-2 in 1995 (Burrows et al., 1999) has footprints ranging from $960 \mathrm{~km} \times 80 \mathrm{~km}$ to $320 \mathrm{~km} \times 40 \mathrm{~km}$ (across $\times$ along track) providing daily coverage in three days. The SCanning Imaging Absorption SpectroMeter for Atmospheric CHartographY (SCIAMACHY), a joint German-Dutch-Belgian instrument launched in 2002 (Bovensmann et al., 1999) on board Envisat has a footprint on Earth ranging from $30 \mathrm{~km} \times 30 \mathrm{~km}$ to $240 \mathrm{~km} \times 30 \mathrm{~km}$ (across $\times$ along track) providing daily coverage in six days. The Ozone Monitoring Instrument (OMI), a DutchFinnish contribution to the NASA EOS-AURA mission, launched in 2004 (Levelt et al., 2000), has a footprint of only $24 \mathrm{~km} \times 13 \mathrm{~km}$ (across $\times$ along track). The three planned operational GOME-2 instruments which will be part of the Eumetsat Polar System (MetOp) for a 15-year period from 2006 onwards will have a footprint of $80 \mathrm{~km} \times 40 \mathrm{~km}$ (across $x$ along track). The increasing potential of the instruments for air quality applications including detection of emissions areas is illustrated by the subsequent observations on tropospheric $\mathrm{NO}_{2}$ (Leue et al., 2001; Richter and Burrows, 2002; Boersma et al., 2004; Martin et al., 2004; Richter et al., 2005, 1).

Future missions focusing on air quality will face choices between sensor resolution, integration time and spatial coverage. A compromise between these must be found. For example, resolution may be sacrificed in order to obtain global coverage or a better signal-to-noise ratio. The planned operational measurements by GOME-2 have not been developed for air quality applications (but for total ozone monitoring) and the resolution has been judged insufficient for the development of an adequate air quality monitoring system from space (Kelder et al., 2005). For a good definition of future missions the need exists to better estimate the quality of the information on the lowest parts of the atmosphere as a function of sensor resolution, taking into account cloud effects.

In this study we have quantified the increase in number of useful footprints, i.e. footprints with sufficient sensitivity to trace gases in the lower troposphere, as a function of sensor resolution. We have analysed the number of useful footprints for three thresholds on cloudiness: fully cloud-free $(0$ percent), almost cloud-free ( $\leq 5$ percent cloudiness) and significant cloud-free ( $\leq 20$ percent cloudiness). At 20 percent cloudiness the radiance from the cloudy region typically outweighs the radiance from the cloud-free region (Boersma et al., 2004). Our final goal has been to document the probability of finding cloud-free observations not only as a func-

\footnotetext{
${ }^{1}$ See also http://www.knmi.nl/omi.
}

tion of observation resolution, but also as a function of geolocation and season.

For this we followed a similar approach to that of Tjemkes et al. (2003) in that we used high resolution cloud mask observations $(1 \mathrm{~km} \times 1 \mathrm{~km})$ and degraded the cloud mask to a lower resolution. Earlier studies (Harshvardhan et al., 1994; Wielicki and Parker, 1992) degraded their observations to lower resolution and then performed a cloud-detection method. However this requires optimising and validating the cloud-detection method for each different resolution. In contrast to Tjemkes et al. (2003) we attempt to provide an absolute reference on the effects of cloudiness as a function of resolution by using MODIS observations which have higher resolution $(1 \mathrm{~km} \times 1 \mathrm{~km}$ vs. $7.5 \mathrm{~km} \times 7.5 \mathrm{~km})$ and improved cloud detection methods (Ackerman et al., 2002). We focus on globally averages, seasonal variations as well as on two continental regions with very different cloud regimes: Europe and northern South-America.

The structure of this paper is as follows. In Sect. 2 we describe the data and analysis method. Section 3 starts with the results on global averages as well as seasonal variations, continuing with a focus on two continental regions: Europe and northern South-America. In Sect. 4 we compare our results with earlier work and describe the limitations of our study. We finish with conclusions in Sect. 5.

\section{Method}

\subsection{MODIS}

The MODIS (MODerate resolution Imaging Spectroradiometer) instrument operates on-board two different satellites: TERRA (EOS AM) and AQUA (EOS PM). TERRA is in a sun-synchronous, near-polar, descending orbit at $705 \mathrm{~km}$ and has an equator crossing time of 10:30 UT. AQUA is in a sun-synchronous, near-polar, ascending orbit at $705 \mathrm{~km}$ and has an equator crossing time of 13:30 UT. Both individually cover the entire Earth's surface every 1 to 2 days, with a swath of $2330 \mathrm{~km}$ across track and a field of view $10 \mathrm{~km}$ along track (at nadir), with spatial resolution between $250 \mathrm{~m} \times 250 \mathrm{~m}, 500 \mathrm{~m} \times 500 \mathrm{~m} 1 \mathrm{~km} \times 1 \mathrm{~km}$, depending on wavelength band. We have used TERRA data in our study and made some comparisons with AQUA data to confirm our findings and investigate the diurnal variation of cloudiness.

\subsection{MODIS cloudmask}

For this study we used the Level 2 MODIS Cloud Mask product at $1 \mathrm{~km} \times 1 \mathrm{~km}$ spatial resolution (MOD35, collection 004). The MODIS cloud detection algorithm employs a combination of different tests on the visible and infrared channels to indicate various confidence levels that an unobstructed (=cloud-free) view of the Earth's surface is observed, divided into domains according to surface type and solar illumination. These tests are reflectance thresholds 
(for $0.66,0.8,1.38 \mu \mathrm{m}$ ), reflectance ratios $(0.87 / 0.66 \mu \mathrm{m}$ ), brightness temperature thresholds (for 6.7, 11, 13.9 $\mu \mathrm{m}$ ) and brightness temperature differences (between 11-6.7, 3.7-12, 8.6-11, 11-12 and, 11-3.9 $\mu \mathrm{m})$. Also a spatial variability test over water has been included (Ackerman et al., 2002). The different tests return a confidence level from 1 (high confidence the pixel is clear) to 0 (high confidence the pixel is cloudy). The individual confidence levels must be combined to determine a final decision on clear or cloudy. As several tests are not independent of each other, tests are split into 5 groups to maximize independence and for each group the minimum confidence determined. The groups are based upon simple IR threshold, brightness temperature difference, solar reflectance, NIR thin cirrus and IR thin cirrus test, respectively. The final cloud mask is then determined from the product of the results of each group. This approach is clear-sky conservative, minimizing clear detection but missing clear regions that spectrally resemble cloud conditions.

Validating cloud masks is difficult, yet several papers address the accuracy of the MODIS Cloud Mask (MOD35) by comparing it with other algorithms. Ackerman et al. (2002) show that the MODIS cloud mask agrees between $86-92 \%$ with groundbased measurements. Berendes et al. (2004) shows an $80 \%$ agreement with ARM measurements, but attributes the difference due to difficulty of detecting low fog above the snowy Arctic (an area which is excluded from this study) and MODIS better cirrus-detection. Heidinger et al. (2004) shows how MODIS improves the capability to detect clear scenes over AVHRR methods. Thomas et al. (2004) shows the global MODIS cloud amount to be $8 \%$ higher than AVHRR on average, but most of this difference is due to differences on high latitudes (which are excluded from this study). These differences are likely an actual improvement due to MODIS improved spectral information (Thomas et al., 2004).

The MODIS cloud mask gives 4 possible confidence levels: confident clear, probably clear, probably cloudy, and confident cloudy, with a 99\%, 95\%, 66\% and less than $66 \%$ confidence of clear, respectively. The lower confidence values are often found at the edges of clouds, and indicate partially cloudy scenes. Most of the mentioned validation studies grouped confident clear with probably clear together as "clear" and probably cloudy with confident cloudy as "cloudy", as considering only confident clear as "clear" results in a large overestimation in cloud cover, while considering only confident cloud as "cloud" results in many overlooked clouds. As such in this study we also grouped confident clear with probably clear together as "clear" and probably cloudy with confident cloudy as "cloudy". Several auxilary data sets are provided with the MODIS cloud mask data (MOD35), such as geolocations (provided at $5 \mathrm{~km} \times 5 \mathrm{~km}$ ), Quality Assurance and domain. Domains are split in water, coast, land and desert. For our study on cloudiness in relation to air quality observations we have only made a distinction between water (open ocean/sea) and the combination of the desert, land and coast domains. Other auxiliary data by MODIS (such as which tests have exactly been performed, presence of shadow or snow/ice, etc.) is provided but not used in this study.

\subsection{Data analysis}

MODIS cloud mask data is delivered in granules of $2330 \mathrm{~km}$ across track and 2030 or $2040 \mathrm{~km}$ along track at $1 \mathrm{~km} \times 1 \mathrm{~km}$ resolution (at nadir). Each MODIS scan (10 km along track) fans out toward the side of each sweep in the form of a bowtie. The across track resolution becomes lower at the sides of each sweep up to around $10 \mathrm{~km}$. As such we decided to discard the outer $290 \mathrm{~km}$ of both sides of the scan, keeping across track resolution smaller than $1.7 \mathrm{~km}$. The next step was to re-grid the MODIS observation to a regular $1 \mathrm{~km} \times 1 \mathrm{~km}$ grid. MODIS geolocations (provided at $5 \mathrm{~km} \times 5 \mathrm{~km}$ ) were also interpolated to the same $1 \mathrm{~km} \times 1 \mathrm{~km}$ grid. Granules containing more than 50 faulty (as indicated by the MODIS Quality Assurance) pixel-rows in the alongtrack direction (which equals $3.6 \%$ of the total granule) were discarded.

Larger footprints were simulated by combining several adjacent $1 \mathrm{~km} \times 1 \mathrm{~km}$ observations depending on the area of the simulated footprint. The different simulated footprints always contain an odd numbers of original $1 \mathrm{~km} \times 1 \mathrm{~km}$ observations, allowing the use of more efficient computer algorithms. The resolutions have been chosen to represent a good sample of resolutions for future and current missions: $3 \times 3,5 \times 5,9 \times 9,11 \times 11,21 \times 21,41 \times 41,61 \times 61,99 \times 99$ $(\mathrm{km} \times \mathrm{km})$, or footprint areas of, respectively, 9, 25, 81, 121, $441,1681,3721$, and $9801 \mathrm{~km}^{2}$. Footprints containing a faulty observation according to MODIS Quality Assurance, were discarded.

A footprint was designated cloudy when a single MODIS observation within the footprint was "cloudy" ( $0 \%$ clouds allowed). If $5 \%$ or less of the MODIS observations were "cloudy" within a footprint, the footprint was designated 5\% cloudy. Similarly for $20 \%$ cloudy. The thresholds "up to 5\%" and "up to 20\%" were determined in addition to the strict cloud free threshold as trace gas retrievals are not equally sensitive to clouds and some can compensate for a small amounts of clouds. For example, in the determination of $\mathrm{NO}_{2}$ a cloud fraction up to $20 \%$ can be compensated for (Boersma et al., 2004), while the strict cloud-free threshold is being applied for the retrieval of a well-mixed gas as methane (Meirink et al., 2005; Gloudemans et al., 2005). The number of cloud-free observations for intermediate threshold values can be easily estimated.

Edge effects can cause unwanted statistic fluctuations when breaking up a scene into equal-sized non-overlapping footprints. For example, a cloud slightly smaller than the simulated footprint can, in one extreme case, fall either fully within a footprint or, in the other extreme case, cover the corner of four footprints, causing all four footprints to be 


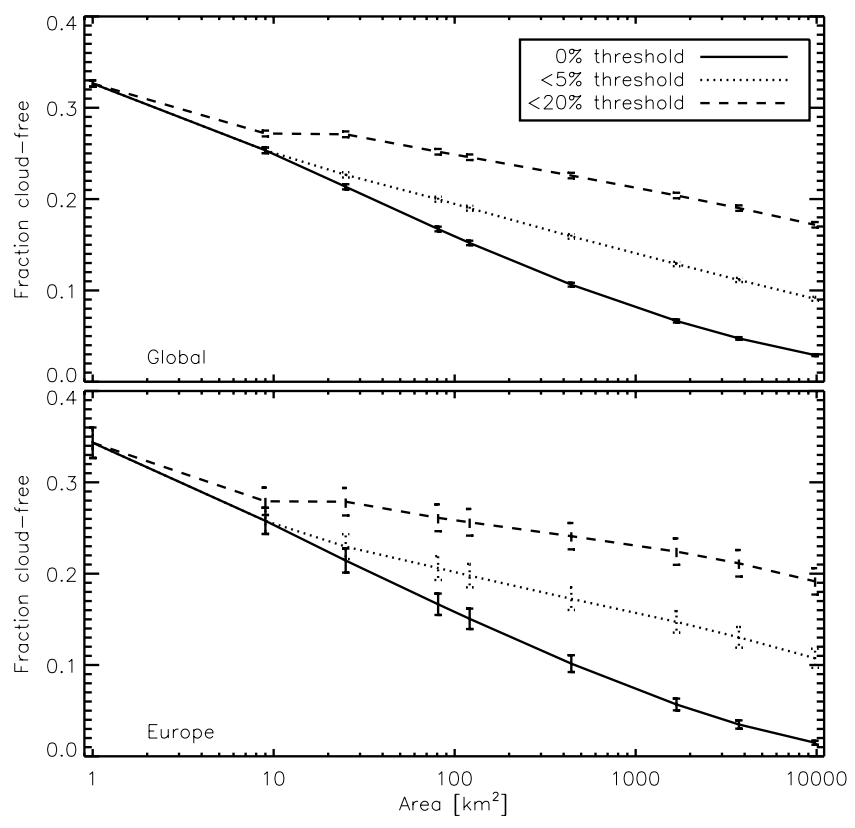

Fig. 1. The fraction of cloud-free observations as a function of sensor resolution (footprint area), as determined from $1 \mathrm{~km} \times 1 \mathrm{~km}$ resolution MODIS TERRA (local overpass time 10:30 UT) cloud mask (MOD35) observations. For each month in 2004 four days (either the 1 st or 2 nd, the 8th, 15th and 22nd) are analyzed and statistics determined. Different line-styles indicate different thresholds on cloudiness: $0 \%$ indicates that not a single MODIS cloud of $1 \mathrm{~km} \times 1 \mathrm{~km}$ was allowed to be present in the observed area. The data for the $5 \%$ and $20 \%$ thresholds includes the areas that were containing clouds up to $5 \%$ and $20 \%$, respectively, of the total area observed. Also indicated are the standard deviations on the average derived from the temporal variability during the whole year (based on 48 days). Top panel: globally averaged between latitudes of $70^{\circ} \mathrm{S}$ and $70^{\circ} \mathrm{N}$. Bottom panel: the same plot but averaged over Europe (latitude range $35^{\circ} \mathrm{N}-73^{\circ} \mathrm{N}$; longitude range $10^{\circ} \mathrm{W}-36^{\circ} \mathrm{E}$ ) for MODIS categories land, coast, and desert. Coincidently, these cloud-free fractions over Europe are very similar to the global averaged fractions in the upper panel that also include the oceans.

considered cloudy. As such an arbitrarily chosen division grid can cause such random variations in cloudiness. For areas containing many footprints this random effect cancels, but for areas containing only a few simulated footprints this method of sampling can have an important effect on the statistics. As such we performed the analysis for all possible different grid locations (at $1 \mathrm{~km} \times 1 \mathrm{~km}$ resolution) for each MODIS granule. This gives a number of realizations equal to the area of the simulated footprint in square kilometers (as we cannot displace the grid by less than a kilometer due to MODIS $1 \mathrm{~km} \times 1 \mathrm{~km}$ resolution). All realizations were stored and averaged in later steps when required, thus avoiding possible edge effects.

Next for each footprint the average geolocation and domain (desert/land/coast or water) was determined. To pre- serve computer resources the Earth was divided in $1^{\circ} \times 1^{\circ}$ gridcells and the statistics for all footprints within each particular $1^{\circ} \times 1^{\circ}$ grid-cell were stored instead of statistics for all individual footprints.

Because our focus is on solar backscatter satellite measurements we limited us to only daytime (solar zenith angle $<85^{\circ}$ ) observations. Still (almost) global cloud cover statistics can be derived from a single day of MODIS daytime observations. We analyzed for each month in 2004 the first, 8th, 15th and 22nd day and determined the statistics described, using Collection 004 MOD35 Cloudmask data. For 1 February 2004 no MODIS data was available and observations of 2 February were used instead. However given the 1 week intervals between other observations, this one day difference should not affect the results presented in the next section. If MODIS passed multiple times over an area during the observed day only the latest overpass was taken into account to avoid giving double significance to such areas.

\section{Results}

\subsection{Fraction cloud-free observations}

Figure 1 shows the fraction of cloud-free observations as a function of the area of the simulated footprint. The first panel is averaged globally between $70^{\circ}$ North and South, excluding the polar regions. The second panel shows the same information but now averaged over the MODIS categories coast/desert/land over Europe (latitudes between $35^{\circ} \mathrm{N}$ and $73^{\circ} \mathrm{N}$, longitudes between $10^{\circ} \mathrm{W}$ and $36^{\circ} \mathrm{E}$ ). Note the logarithmic area axis. Both panels show three different line-styles (solid, dotted and dashed) for footprints designated 0\%, 5\% cloud fraction or less, and $20 \%$ cloud fraction or less, respectively. Rounding errors occur when observing $9 \mathrm{~km}^{2}$ $(3 \mathrm{~km} \times 3 \mathrm{~km})$. In this case the number for $5 \%$ cloud fraction or less is identical to $0 \%$, because the possible cloud fractions are $0,0.11,0.22,0.33, \ldots$, etc., and the number for $20 \%$ or less is effectively for $11 \%$ or less.

Globally we see a decrease in the fraction of cloud-free observations as a function of area from about one-third at $1 \mathrm{~km} \times 1 \mathrm{~km}$ to only $3 \%$ percent of all observations at $10000 \mathrm{~km}^{2}$. The decrease is almost logarithmically linear up to synoptic scales of several hundred $\mathrm{km}^{2}$ from whereon a further increase in footprint size causes relatively less extra cloud flagging. The numbers above are using the strict cloudiness threshold of $0 \%$, where a single cloudy $1 \mathrm{~km} \times 1 \mathrm{~km}$ MODIS observation within the footprint causes a full footprint to be designated cloudy. By application of a less strict threshold on cloudiness the fraction of cloud-free observations is increased and the decrease with area is less steep. For footprints with up to $5 \%$ and up to $20 \%$ cloudiness we find at $10000 \mathrm{~km}^{2}$ useful fractions of 0.09 and 0.17 , respectively. The latter numbers are roughly applicable to GOME-1 on ERS-2. 


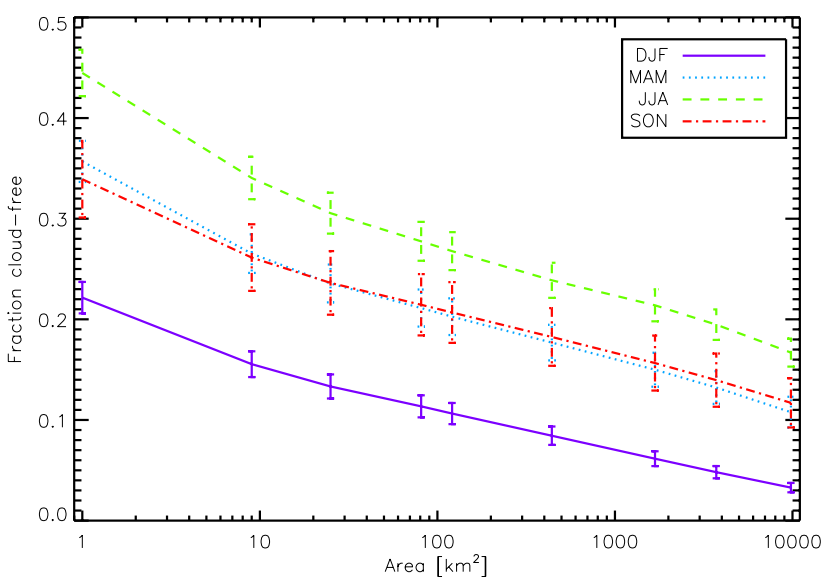

Fig. 2. Similar as Fig. 1, yet now only for the MODIS categories land/desert and coast, over Europe, and with a threshold of up to 5\% cloudiness. Different colors indicate averaging over different seasons: winter: December, January, February (DJF); spring: March, April, May (MAM); summer: JJA (June, July, August); autumn: September, October, November (SON). Also indicated are the standard deviations on the average derived from the temporal variability during the season. Twelve days of global MODIS observations for the year 2004 have been analysed per season.

The lowest panel of Fig. 1 shows that there is, coincidently, little difference between the fraction of cloudfree observations globally and for the MODIS categories land/desert/coast over Europe. For possible future air quality applications for the European continent the fraction of cloudfree observations for, for example, an area of $100 \mathrm{~km}^{2}$ are for the three thresholds ( $0 \%$, up to $5 \%$, up to $20 \%$ ), respectively, $0.16,0.20$, and 0.26 . Numbers at $3200 \mathrm{~km}^{2}$, which are applicable to the GOME-2 instrument, are significantly smaller and down to $4 \%$ for the $0 \%$ threshold. The standard deviations over Europe are larger than globally because of the larger seasonal variability. These are further detailed in the next section.

\subsubsection{Seasonal variability}

Figure 2 shows the same parameter as Fig. 1 (lower panel), but now differentiated between seasons and using "up to 5\%" as cloudiness threshold. For the seasonal averages the data for twelve days (four days per month) have been used: winter is denoted by DJF (December, January, February), spring by MAM (March, April, May), summer by JJA (June, July, August), and autumn by SON (September, October, November). The panel for the global average is not shown as on a global scale the differences between seasons are almost nonpresent, mainly because the northern-hemisphere winter is averaged with the southern-hemisphere summer and in reverse. As such the global cloud cover is well sampled by only 12 days per season. The smaller area of Europe suffers

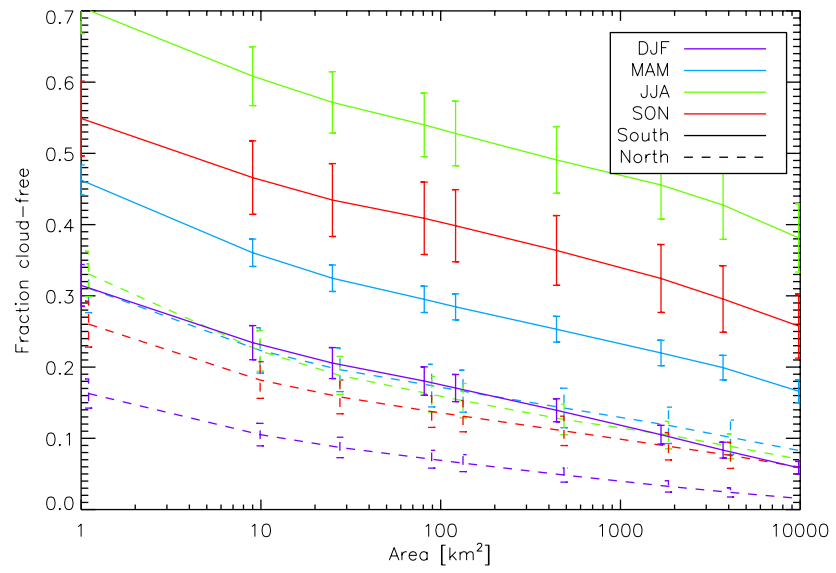

Fig. 3. Similar as Fig. 2, with a threshold of up to $5 \%$ cloudiness, yet now splitted between the land masses of northern (dashed curves) and southern (solid curves) Europe. Indicated are also 1sigma errors-bars derived from the temporal variability during the season. The error-bars from the North Europe observations are shifted slightly in area for clarity.

from large uncertainties due to temporal sampling, but while the absolute value might be more uncertain, the relative decrease or slope is similar for all seasons.

The European winter clearly has the largest amount of clouds of the seasons, spring and autumn less, and not differing much from each other. European summer is relatively the most cloudfree.

\subsubsection{Europe}

In order to illustrate the reliability of our approach, a more detailed study was made of North and South Europe, areas where one knows qualitatively what to expect.

A further refinement of the fraction of cloud-free observations as a function of sensor resolution over Europe can be obtained by differencing not only between the seasons, but also between northern and southern Europe. Because of the rather different cloud climatology significant differences in cloudiness are expected. For this purpose northern Europe has been defined between $46^{\circ} \mathrm{N}-58^{\circ} \mathrm{N}$ and $10^{\circ} \mathrm{W}-36^{\circ} \mathrm{E}$ and southern Europe between $35^{\circ} \mathrm{N}-46^{\circ} \mathrm{N}$ and $10^{\circ} \mathrm{W}-36^{\circ} \mathrm{E}$. Figure 3 illustrates that indeed the fraction of cloud-free observations over southern Europe is typically twice the fraction of cloud-free observations over northern Europe. The summer and autumn over southern Europe give a fraction of cloud-free observations of up to 0.71 and 0.55 , respectively, at $1 \mathrm{~km} \times 1 \mathrm{~km}$, and 0.38 and 0.26 at $10000 \mathrm{~km}^{2}$. The slopes as a function of sensor resolution (area) are rather similar. The standard deviations in the figure show that the daily variations within a season are quite large. The geographical dependence of the results is further emphasized by Fig. 4. This figure illustrates the relative reduction in cloudy observations 


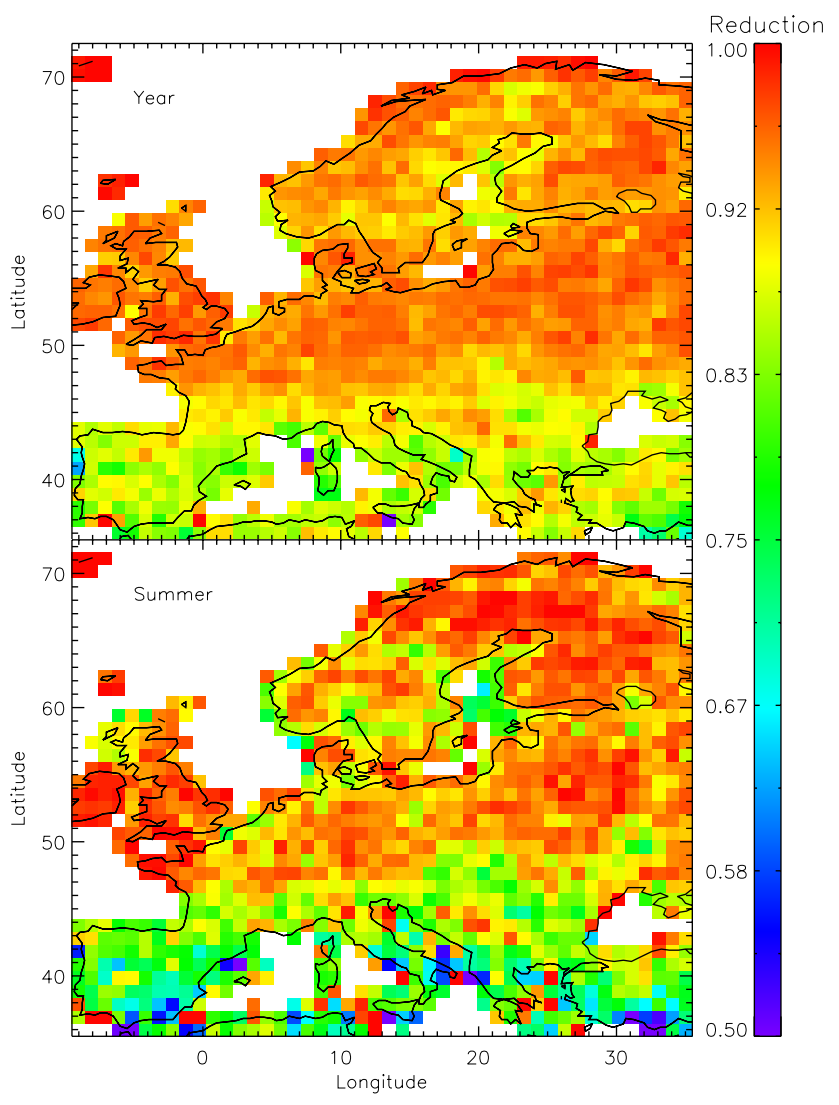

Fig. 4. Relative reduction in clouded observations (up to 5\% cloudiness thresshold) over Europe, when increasing sensor resolution from $3200 \mathrm{~km}^{2}$ to $100 \mathrm{~km}^{2}$. The upper panel shows the reductions averaged over the whole year 2004, the lower panel averaged over the summer (JJA).

when sensor resolution would be increased from $3200 \mathrm{~km}^{2}$ (applicable to GOME-2 on MetOp) to $100 \mathrm{~km}^{2}$. The upper panel shows the relative reduction in cloudy scenes for the summer season, the lower panel shows the yearly averages. Red colors indicate small relative reductions, green and blue significant relative reductions. Clearly the reductions are largest over southern Europe. While the relative reduction in cloud-fractions seems minor, the increase of cloudfree observations due to improving sensor resolution may in fact be quite larger. A better way to quantify the impact of sensor resolution on fraction of cloud-free observations - particularly in persistently cloudy situations - is to calculate a relative gain factor. The relative gain factor is defined as the fraction of cloud-free observations for a sensor resolution of $100 \mathrm{~km}^{2}$ divided by the same value for a sensor resolution of $3200 \mathrm{~km}^{2}$ and is a useful additional parameter as the gain factor puts more weight on extra cloud-free observations in particularly cloudy areas. For example, an area with a yearly cloud cover of $90 \%$ at $3200 \mathrm{~km}^{2}$ resolution and $80 \%$ at $100 \mathrm{~km}^{2}$ resolution, has only a relative cloud
Table 1. Absolute fraction of cloud-free observations (FCF) at $100 \mathrm{~km}^{2}$ resolution and relative gain factor (RGF) between footprints of $100 \mathrm{~km}^{2}$ and $3200 \mathrm{~km}^{2}$ averaged over the summer of 2004 (June, July, August), and the standard devation $(\sigma)$ of the averages due to temporal variability. Threshold: up to $5 \%$ cloudiness.

\begin{tabular}{lcccc}
\hline City & FCF & $\sigma_{\text {FCF }}$ & RGF & $\sigma_{\text {RGF }}$ \\
\hline Athens & 0.62 & 0.04 & 1.33 & 0.16 \\
Rome & 0.41 & 0.05 & 1.41 & 0.26 \\
Madrid & 0.35 & 0.05 & 1.32 & 0.28 \\
Belgrade & 0.31 & 0.04 & 1.36 & 0.30 \\
Moscow & 0.16 & 0.03 & 1.80 & 0.59 \\
Warschau & 0.16 & 0.03 & 1.47 & 0.49 \\
Oslo & 0.16 & 0.03 & 1.56 & 0.52 \\
Paris & 0.13 & 0.03 & 2.09 & 0.83 \\
Amsterdam & 0.07 & 0.02 & 2.49 & 1.51 \\
London & 0.04 & 0.02 & 3.39 & 2.48 \\
\hline
\end{tabular}

reduction of $89 \%$, while the relative gain cloud-free factor is $200 \%$. The drawback for the gain factor is that infinite numbers may occur in grid cells where cloud-free observations are completely absent. Therefore no meaningful geographic images, such as Fig. 4, can be easily shown.

Instead, our interest being in future Earth observation of air quality, we compare gain factors with reduction factors for a number of major cities in Europe, see Table 1. For studying cloud cover over individual cities only twelve days per season do not adequatly sample the temporal variability, as such the factors in Table 1 have been derived from a dataset sampling daily over each city during the summer of 2004 thus capturing the temporal variability. The cities are ordered as a function of their fraction of cloud-free observations. In summer 2004 the cities with the largest fraction of cloud-free observations are Athens (0.62) and Rome (0.41). The gain factors for these cities are 1.33 and 1.41 , respectively. This implies that the number of cloud free observations over these cities would increase by about $35 \%$ using a footprint of $100 \mathrm{~km}^{2}$ instead of $3200 \mathrm{~km}^{2}$ (applicable to GOME-2). The smallest fraction of cloud-free observations at $3200 \mathrm{~km}^{2}$ resolution is found for London (0.04). The number of cloud-free observations in the summer over London increases by more than a factor three for the high spatial resolution $\left(100 \mathrm{~km}^{2}\right)$ case.

\subsubsection{Northern South America}

Air pollution is a global phenomenon. For example, in the tropics the impact of human activities on atmospheric composition is increasing rapidly. Satellite observations of trace gases down to the boundary layer in tropical areas that are mostly poorly sampled by groundbased measurements would offer a wealth of information for studies on global change. In addition, we wondered if in the case of persistently cloudy 


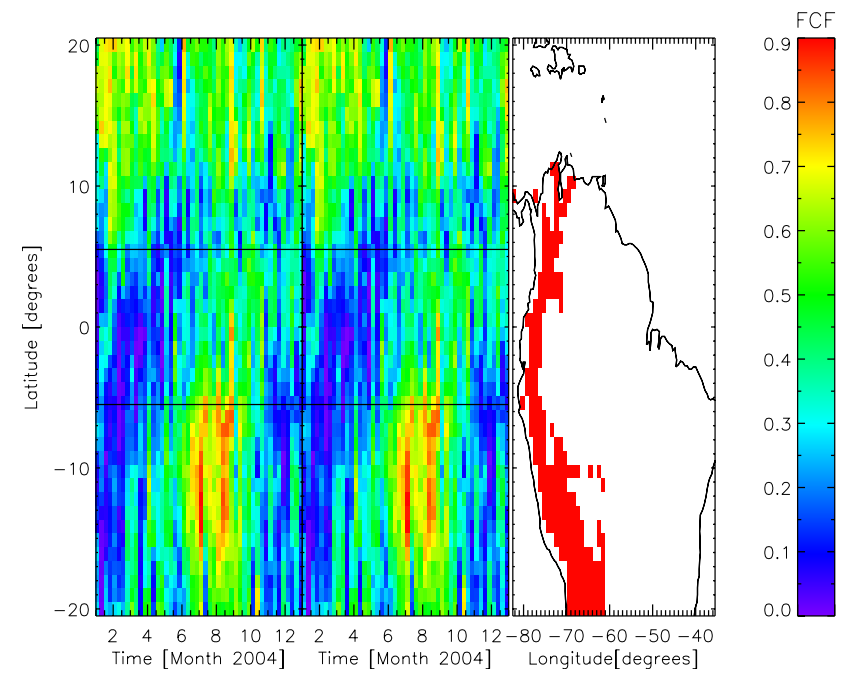

Fig. 5. Yearly variation in 2004 of fraction of cloud-free observations with a threshold up to $5 \%$ cloudiness (FCF) over northern South-America and surrounding waters for different $1^{\circ}$ latitude bands. The plot is presented twice, in order to better show the cyclic yearly variation. On the right side an image of South-America is given (contracted in longitude) with the scenes over the Andes that have been left out, and for visual reference to the latitudes. The highest cloud fractions (in blue) move rather slow from South to North during the year and then quickly from North to South in November/December.

regions an improved sensor resolution would help to obtain more useful (= cloud-free) observations. We thereto decided to investigate the area of the Amazon rain forest, often clouded due to the Intertropical Convergence Zone (ITCZ).

The cloud statistics based on MODIS data for 2004 over South-America and in more particular the Amazon area was used. For the analysis the observations are split into two seasons (wet and dry). Our division in seasons is based on examination of the MODIS cloud statistics for 2004.

First we arbitrarily broke up the land-mass of northern South-America into three regions: South $\left(20^{\circ} \mathrm{S}-5^{\circ} \mathrm{S}\right)$, Equator $\left(5^{\circ} \mathrm{S}-5^{\circ} \mathrm{N}\right)$, and North $\left(5^{\circ} \mathrm{N}-20^{\circ} \mathrm{N}\right)$ as indicated by solid lines in Fig. 5. Note that the northern region contains only a small area of landmass. Observations over the Andes (indicated in red in the right-hand side panel) have been removed in order to prevent orography effects. As the centre of convection moves in latitudinal direction during the year, the three different regions experience wet and dry seasons during different periods in the year (Hastenrath, 1997).

Figure 5 illustrates the yearly variation of fraction of cloud-free observations over South-America for 2004. The same plot is shown twice in order to better show the annual cycle. For the purpose of our study the period during which a region has a low fraction of cloud-free observations will be referred to as the "wet season". Similarly, the period during which the fraction of cloud-free observations is high will be

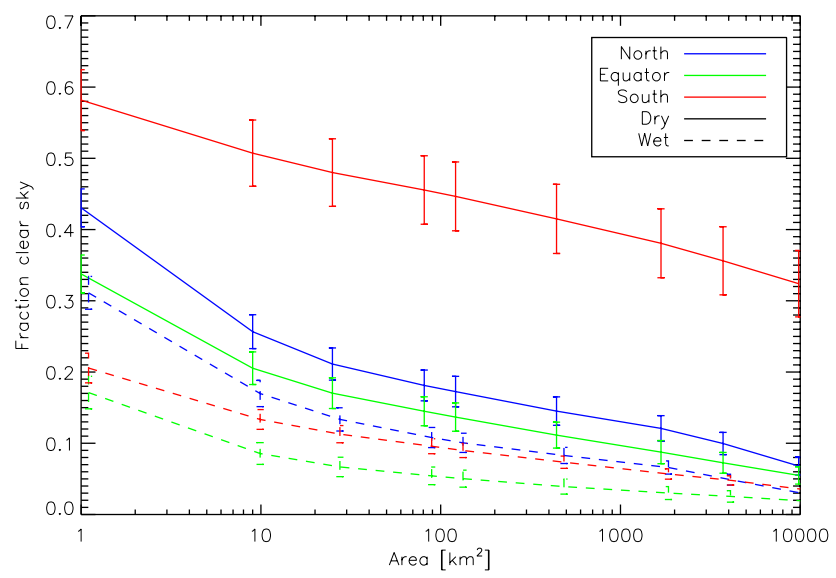

Fig. 6. Similar as Fig. 1, but now over northern Southern America. The fraction of cloud-free observations is shown for different subregions (blue, North $\left[5^{\circ} \mathrm{N}-20^{\circ} \mathrm{N}\right]$, Equator $\left[5^{\circ} \mathrm{S}-5^{\circ} \mathrm{N}\right]$ and South $\left[20^{\circ} \mathrm{S}-5^{\circ} \mathrm{S}\right]$ ) and seasons (solid curves: dry season, dashed curves: wet season). The area covered by the Andes has been removed. Indicated are also 1-sigma errors-bars derived from temporal variability during seasons.

referred to as the "dry season". In this manner the dry season is defined to last for the northern region from January to March and August to October, for the Equator regions from June till November and for the southern region from May till October. It is acknowledged that the division in (multiple) dry and wet seasons could have been made somewhat more thoroughly. However, the main driver for the present study is to obtain a subtantial difference in cloud statistics between the seasons. Our division is roughly in line with the division in wet and dry seasons as reported in the literature (Hastenrath, 1997).

Figure 6 shows the fraction of cloud-free observations over land and averaged over the wet and dry seasons for the different regions. Again observations over the Andes have been removed. As desired the wet seasons show a much lower fraction of cloud-free observations than the dry seasons, most clearly in the southern region. Northern SouthAmerica is showing more seasonal variability than Europe: the wet season is comparable in cloudiness to the European winter (Fig. 2), while the dry season compares to the autumn in southern Europe (Fig. 3). This is well in line with Asner (2001) who investigated the seasonal variation in cloudiness over the Brazilian Amazon using Landsat images $(\sim 30 \mathrm{~m}$ resolution) of $185 \mathrm{~km} \times 185 \mathrm{~km}$.

Figure 7 is similar to Fig. 4 for Europe. The geographical distribution of the reduction in cloudy scenes is presented for an increase in sensor resolution from $3200 \mathrm{~km}^{2}$ to $100 \mathrm{~km}^{2}$. The upper and lower panel show the reductions for the dry and wet season, respectively, for each of the three defined regions. The reduction in cloudy scenes in the dry season is substantial, while reductions in the wet season are only 


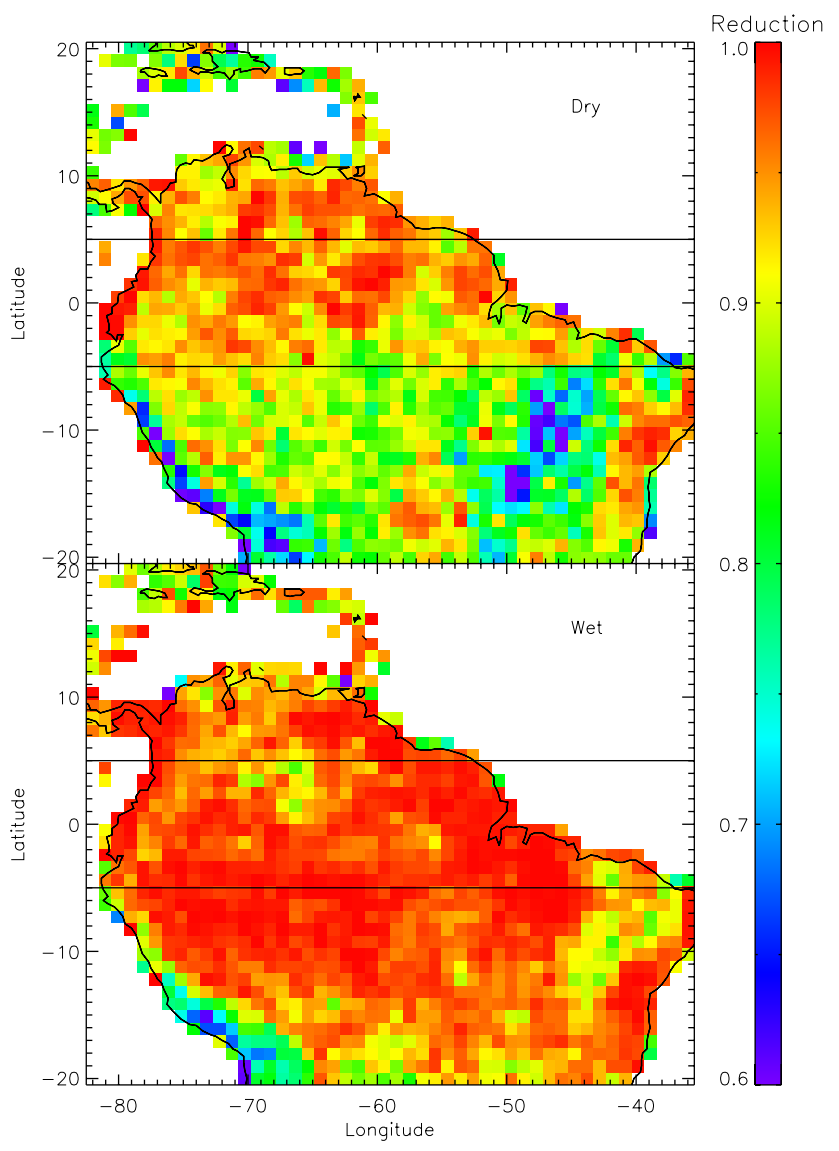

Fig. 7. Similar as Fig. 4, but now showing the relative reduction in clouded observations during the dry (upper panel) and wet (lower panel) season over the northern South America.

marginal. However, this should be compared with the results in terms of a gain factor, again defined as the number of cloud-free observations in a $1 \mathrm{~km} \times 1 \mathrm{~km}$ grid cell for a sensor resolution of $100 \mathrm{~km}^{2}$ divided by the same value for a sensor resolution of $3200 \mathrm{~km}^{2}$. In Table 2 the absolute fraction of cloud-free observations as well as their associated gain factors are presented as a function of the three different latitude bands in the region. The gain factors show that also in the wet seasons significant more cloud free observations are obtained with increased resolution. While the fraction of cloud-free observations remains small, the number of cloud free observations is calculated to exceed almost twice the number of lower resolution observations in each latitude band.

We conclude that also above persistently clouded regions (in the tropical regions) a high sensor resolution will improve sensitivity to trace gases in the lower troposphere by looking between clouds.
Table 2. Absolute fraction of cloud-free observations (FCF) at $100 \mathrm{~km}^{2}$ resolution and relative gain factor (RGF) between footprints of $100 \mathrm{~km}^{2}$ and $3200 \mathrm{~km}^{2}$ for wet and dry season over South America averaged for three different indicated latitude bands. Threshold: up to 5\% cloudiness.

\begin{tabular}{rcccc}
\hline $\begin{array}{r}\text { Latitude } \\
\text { band }\end{array}$ & $\begin{array}{r}\text { FCF } \\
\text { Dry }\end{array}$ & $\begin{array}{r}\text { RGF } \\
\text { Dry }\end{array}$ & $\begin{array}{r}\text { FCF } \\
\text { Wet }\end{array}$ & $\begin{array}{r}\text { RGF } \\
\text { Wet }\end{array}$ \\
\hline $5^{\circ}-20^{\circ}$ & 0.17 & 1.64 & 0.10 & 1.89 \\
$-5^{\circ}-5^{\circ}$ & 0.14 & 1.79 & 0.05 & 1.89 \\
$-20^{\circ}--5^{\circ}$ & 0.45 & 1.23 & 0.09 & 1.79 \\
\hline
\end{tabular}

\subsection{Error analysis}

The main contributors to the uncertainty or error are the temporal variability and MODIS cloud mask uncertainty. Errors due to temporal variability are presented in the standard deviations where possible.

Even though the MODIS cloud scene analysis method is one of the most advanced cloud detection schemes (Ackerman et al., 2002), some uncertainties might remain, but MODIS validation shows that MODIS compares well to independent observations (see Sect. 2.2).

In most of the mentioned validation papers the confident clear $(99 \%)$ and probably clear (95\%) MODIS scenes were designated cloud-free, noting that the MODIS cloud mask gives 4 possible confidence levels: confident clear, probably clear, probably cloudy, and confident cloudy, with a $99 \%, 95 \%, 66 \%$ and less than $66 \%$ confidence of a clear scene, respectively. We therefore adopted the same criteria in our study. Nonetheless, one can determine the effect of this choice on the results. As such the analysis were redone but now for all three MODIS confidence levels (the fourth confidence level is equivalent to all scenes being flagged clouded, resulting in a constant fraction of cloud-free observations of zero). When instead of $95 \%$, the $99 \%$ or more confidence level was used to flag clear scenes, the fraction of cloud-free observations drops for all footprint sizes with a almost constant factor of $0.73 \pm 0.06$, while the slope remains constant. Employing the 66\% confidence level results in much more clear scenes and thus a larger fraction of cloud-free observations, again with the same slope as the results obtained with the $95 \%$ confidence level, but offset by a relative factor of $1.23 \pm 0.05$. The standard deviation due to temporal variability is quite insensitive to the confidence level remaining almost constant with respect to changes in confidence level employed in all cases. Most importantly however the slope or relative reduction as function of footprint area remains constant. This means that the relative gain from increasing sensor resolution can be determined unambigiously.

Moreover, visual inspection of the MODIS real color images shows that considering only confident clear as "clear" 
results in the detection of many small non-existent clouds, while considering only confident cloud as "cloudy" results in many overlooked clouds. As such the choice to designate all scenes with a $95 \%$ confidence or more as clear is considered to best represent the "real" cloud cover. This choice is also consistent with the use in MODIS validation studies (see Sect. 2.2).

\section{Discussion}

\subsection{Earlier work}

It is interesting to compare our results with earlier works, both in absolute number of cloud-free observations and in its dependence on footprint area. For example, in the ACECHEM study (2001) global average statistics for a single day (4 July 1996) was derived from $1 \mathrm{~km} \times 1 \mathrm{~km}$ ATSR2 images. Our fraction of cloud-free observations based on 48 days of global data from MODIS TERRA are somewhat lower, yet the difference decreases when comparing only the fraction of cloud-free observations for July 2004 (22\% vs. $14 \%$ at $1600 \mathrm{~km}^{2}$, respectively) while the change with sensor resolution is almost identical. Therefore, the MODIS cloud screening procedures that is applied here is likely more stringent and makes use of the full suite of MODIS observations at different wavelengths, as MODIS has more channels than ATSR-2. As the ACECHEM study analysed only a single day, temporal variation might also confuse direct comparison.

In another study by Tjemkes et al. (2003), per season one week of cloud mask data from a geosationary platform was studied. They found that the fraction of cloud-free observations values are twice as large as in our study, yet with similar change with sensor resolution. Yet their study did not try to establish an absolute reference. The employed cloud-mask might underestimate the number of clouds as the cloud-detection algorithm was designed for SEVIRI on Meteosat Second Generation (Meteosat-8), but applied on its predecessor, MVIRI on Meteosat-7. MVIRI contains only three observation channels. The MODIS cloud mask algorithm used in our study is more advanced because it can make use of much more spectral channels, see the specifications in Sect. 2.2. Also the initial cloudmask of MODIS is of higher sensitivity due to MODIS better resolution $(1 \mathrm{~km} \times 1 \mathrm{~km})$ compared to MVIRI $(7.5 \mathrm{~km} \times 7.5 \mathrm{~km})$. All cloud detection methods sometimes overlook a cloud that covers only a very small area of the total footprint, as such very small clouds might be missed by MVIRI but not by MODIS. Finally MODIS is cloud conservative, as shown by Li et al. (2005), which is a desired property of cloud mask employed to remove cloudy observations.

Our study agrees with earlier studies which analyzed cloud fractions for a single resolution, such as Bréon et al. (2005), who found at $7 \mathrm{~km}$ along-track resolution using GLAS ob- servations around 30\% "almost clear sky" (aerosols and clouds $\tau<0.2$ ) over Europe and $\sim 32 \%$ globally during autumn 2003. The corresponding numbers from our study are $27 \%$ and $28 \%$, respectively, which correspond very well given the uncertainties. Meerkötter et al. (2004) found, using 14-years of AVHRR and SYNOP observations, and at $1 \mathrm{~km} \times 1 \mathrm{~km}$ resolution, for northern Europe a yearly fraction of cloud-free observations around 35\% and for southern Europe around 55\%. The corresponding numbers from our study are $27 \%$ and $50 \%$, respectively, which correspond very well given the larger uncertainties as they study smaller areas (individual countries). As such they confirm the differences we found between northern and southern Europe. Using $7 \mathrm{~km} \times 5 \mathrm{~km}$ Meteosat observations spanning from $\mathrm{Au}-$ gust 1994 till July 1995 Massons et al. (1998) found an annual fraction of cloud-free observations over northern Europe between $10-40 \%$ and over southern Europe between $40-70 \%$, which compares very well with our results of $27 \%$ and $50 \%$, respectively.

\subsection{Data uncertainties}

As discussed in Sect. 2.2, validation studies have shown the MODIS Cloud Mask to be in good agreement with groundbased measurement and even improve on other existing cloud detection satellite instruments. As such we have high confidence in the MODIS cloud mask data. Also the information provided by the MODIS Cloud Mask allowed a study of the effect of employing different confidence levels for determining cloud cover. Although different confidence levels change the absolute value of the fraction of cloud-free observations, the relative decrease as function of footprint (slope) remains the same, as shown in Sect. 3.2. Visual inspection of the data with real color images and other validation studies confirm our choice of designating all scenes with a $95 \%$ confidence or more as clear.

This study was limited to data from one year, 2004, and within this year, we examined four days of MODIS data per month: the 1st (or 2nd), 8th, 15th and 22nd day. It is therefore unlikely that our data set covers the full temporal variability in cloudiness. For example, we noted that on 15 April 2004 central Europe was relatively cloud free. However, we assume that the effect of imperfect temporal sampling will be smaller when we average over a large enough area, capturing enough spatial variability to compensate for the temporal variability. E.g., while central Europe was cloud-free, northern Europe was quite clouded. We did some tests (not shown here) which confirmed that the effects of our limited temporal sampling does not affect the results when we look at averages over areas of a single (sub-)continent or larger.

We also analyzed MODIS/AQUA observations for the 15 th of each month, searching for diurnal variation, as MODIS/TERRA has a local overpass time of 10:30 and MODIS/AQUA at 13:30. However we found very little difference within the uncertainties. From this we tend 
to conclude that the considered overpass times would be equally adequate for missions focusing on air quality. It is noted that to study diurnal variation it would be preferably to employ a single instrument because the construction of different instruments may introduce (technical) differences, even if of similar design. Also a larger time difference (e.g. between 10:30 and 16:00) would be needed for a proper study of diurnal variations in cloudiness. In this study we chose to analyse observations from MODIS/TERRA because MODIS/AQUA is missing a channel and because MODIS/TERRA is in descending orbit, similarly as GOME, SCIAMACHY, and GOME-2.

In this work we did not study the effect of cirrus clouds that are optically thin (optical thickness $<0.2$ ) in the visible wavelength range but well observed in the infrared. Thin cirrus clouds can significantly influence retrievals of trace gas constituents. Cirrus clouds occur most frequently at higher altitudes $(>10 \mathrm{~km})$ and in the tropics and less often at lower altitudes $(\sim 6 \mathrm{~km})$ and at mid-latitudes. The MODIS cloud mask product gives information on the possible presence of optically thin clouds. Based hereon we concluded that thin cirrus occur globally for less than $4 \%$ of all otherwise clear sky scenes. For Europe we find less than $2 \%$. In a recent study by Breon et al. (2005) using Geoscience Laser Altimeter System (GLAS) observations $(7 \mathrm{~km}$ along track resolution) it is shown that optical thin $(<0.2)$ clouds occur for about $8 \%$ of the scenes in the tropics and also much less at mid-latitudes.

Finally, shadowing of clouds could have an impact on the determination of the fraction of cloud-free scenes. Based on our (limited) MODIS data-set we conclude that shadowing will impact on the number of cloud-free scenes by less than $4 \%$ globally, and less than $0.5 \%$ over Europe.

\section{Conclusions}

Recent satelliteborne trace gas column observations sensitive to the lower troposphere and planetary boundary layer show large potential for air quality applications (e.g. by constraining air quality analyses and forecasts) and for studies on human impact and global change (e.g. by surface emission inversions). Envisioned applications require footprints that are minimised for the effect of clouds. In this paper we have investigated the potential to increase the fraction of cloud-free observations by an increase in sensor resolution. We have quantified the benefits globally and for two regions with very different cloud regimes: Europe and northern South America. We used the $1 \mathrm{~km} \times 1 \mathrm{~km}$ MODIS TERRA cloud mask for our calculations. We have also demonstrated that the relative gain in cloud-free observations as a function of sensor resolution is largest in the more cloudy regions and seasons.

In our study we have quantified the "fraction of cloud-free observations" and the increase of cloud-free observations for higher sensor resolutions. Under the assumption of a pre- served sampling rate (that is, e.g., related to revisit time and swath) a doubling of sensor resolution would imply by definition a doubling of the absolute number of cloud-free observations over a certain area. This factor is typically larger than the change in cloud fraction and easy to quantify. Combined with the increase of useful cloud-free footprints this allows e.g., a future mission with $10 \mathrm{~km} \times 10 \mathrm{~km}$ footprint and similar swath to GOME-2 to statistically obtain as much cloud-free measurements over Northwest Europe in less than a week as GOME-2 obtains in a full year.

Finally, the absolute number of cloud-free observations over a certain region can be increased by increasing the revisit time of the observations. This can be accomplished in different ways. First, by using a wide swath. For example, the wide swath of OMI and MODIS yield global coverage in one day while GOME-1 on ERS-2 only obtained global coverage in three days. An instrument could also be positioned on a geostationary platform or in low-inclination orbit instead of the more common polar orbit. These configurations would in addition allow to observe diurnal variations in trace gas concentrations. The absolute number of cloudfree observations using these geometries will not increase if the clouds persist over the whole day. A similar study as presented here, but using cloud mask data from instruments on a geostationary platform is needed to quantify to what extend the number of cloud-free observations for certain regions would be increased by performing multiple observations per day. Diurnal variation in cloudiness changes from day-to-day, depending on the weather, and is a function of geolocation and season.

Acknowledgements. We would like to thank J. de Laat and the referees for their comments. The MODIS data used in this study were acquired as part of the NASA's Earth Science Enterprise. The MODIS cloud mask algorithms were developed by the MODIS Science Teams. The MODIS cloud mask data were processed by the MODIS Adaptive Processing System (MODAPS) and Goddard Distributed Active Archive Center (DAAC), and are archived and distributed by the Goddard DAAC. The authors have obtained additional and more specialised statistics from the presented data, e.g., concerning different observation techniques or cloud thresholds. Those interested in using these additional cloud-statistics from the used dataset can contact the first author.

Edited by: U. Pöschl

\section{References}

Ackerman, S. A., Strabala, K. I., Menzel, W. P., Frey, R. A., Moeller, C. C., Gumley, L. E., Baum, B., Wetzel-Seeman, S., and Zhang, H.: Discriminating clear sky from clouds with MODIS Algorithm Theoritical Basis Document (MOD35), Tech. Rep. ATBD-MOD-06, University of Wisconsin-Madison, 2002.

Asner, G.: Cloud cover in Landsat observations of the Brazilian Amazon, Int. J. Rem. Sens., 22, 3855-3862, 2001.

Berendes, T. A., Berendes, A., Welch, R. M., Dutton, E. G., Uttal, T., and Clothiaux, E. E.: Cloud Cover Comparisons of the 
MODIS Daytime Cloud Mask with Surface Instruments at the North Slope of Alaska ARM Site, IEEE Trans. Geosci. Rem. Sens., 42, 2584-2592, 2004.

Boersma, K. F., Eskes, H. J., and Brinksma, E. J.: Error analysis for tropospheric $\mathrm{NO}_{2}$ retrieval from space, J. Geophys. Res.-Atmos., 109, D04 311-D04 322, 2004.

Bovensmann, H., Burrows, J. P., Buchwitz, M., Frerick, J., Noel, S., Rozanov, V. V., Chance, K. V., and Goede, A. P. H.: Sciamachy: Mission objectives and measurement modes, J. Atmos. Sci., 56, 127-150, 1999.

Bréon, F. M., O’Brien, D. M., and Spinhirne, J. D.: Scattering layer statistics from space borne GLAS observations, Geophys. Res. Lett., 32, 22 802, doi:10.1029/2005GL023825, 2005.

Burrows, J. P., Dehn, A., Deters, B., Himmelmann, S., Richter, A., Voigt, S., and Orphal, J.: Atmospheric remote-sensing reference data from GOME: 2, Temperature-dependent absorption cross sections of $\mathrm{O}_{3}$ in the 231-794 nm range, J. Quant. Spectrosc. Radiat. Trans., 61, 509-517, 1999.

ESA: The five candidate earth explorer core missions, Reports for Assessment, ACECHEM, Tech. rep., ESA, 2001.

Gloudemans, A. M. S., Schrijver, H., Kleipool, Q., van den Broek, M. M. P., Straume, A. G., Lichtenberg, G., van Hees, R. M., Aben, I., and Meirink, J. F.: The impact of SCIAMACHY nearinfrared instrument calibration on $\mathrm{CH} 4$ and $\mathrm{CO}$ total columns, Atmos. Chem. Phys., 5, 1733-1770, 2005, http://www.atmos-chem-phys.net/5/1733/2005/.

Harshvardhan, B. A., Wielicki, B. A., and Ginger, K. M.: The Interpretation of Remotely Sensed Cloud Properties from a Model Parameterization Perspective, J. Climate, 7, 1987-1998, 1994.

Hastenrath, S.: Annual cycle of upper air circulation and convective activity over the tropical Americas, J. Geophys. Res., 102, 42674274, 1997.

Heidinger, A. K., Rao Anne, V., and Dean, C.: Using MODIS to Estimate Cloud Contamination of the AVHRR Data Record, J. Atmos. Oceanic Technol., 19, 586-601, 2004.

Kelder, H., van Weele, M., Bovensmann, H., Goede, A., Kerridge, B., Mager, R., Monks, P., Reburn, W., Remedios, J., and Sassier, H.: Operational Atmospheric Chemistry Monitoring Missions: CAPACITY, final report, ESA contract no. 17237/03/NL/GS, Tech. rep., ESA, 2005.

Koelemeijer, R. B. A. and Stammes, P.: Effects of clouds on ozone column retrieval from GOME UV measurements, J. Geophys. Res., 104, 8281-8294, 1999.

Leue, C., Wenig, M., Wagner, T., Klimm, O., Platt, U., and Jähne, B.: Quantitative analysis of $\mathrm{NO}_{\mathrm{x}}$ emissions from Global Ozone Monitoring Experiment satellite image sequences, J. Geophys. Res., 106, 5493-5506, 2001.
Levelt, P. F., van den Oord, B., Hilsenrath, E., Leppelmeier, G. W., Bhartia, P. K., Malkki, A., Kelder, H., van der A, R. J., Brinksma, E. J., van Oss, R., Veefkind, P., van Weele, M., and Noordhoek, R.: Science Objectives of EOS-Aura's Ozone Monitoring Instrument (OMI), in: Proc. Quad. Ozone Symposium, pp. 127-128, 2000.

Li, Z., Crib, M., Chang, F.-L., Trishchenko, A., and Luo, Y.: Evaluating MODIS Cloud Detection Algorithm Using WholeSky Imager Cloud Cover Data at the Three ARM Sites, in: Fifteenth ARM Science Team Meeting Proceedings, Daytona Beach, Florida, 2005.

Martin, R. V., Parrish, D. D., Ryerson, T. B., Nicks, D. K., Chance, K., Kurosu, T. P., Jacob, D. J., Sturges, E. D., Fried, A., and Wert, B. P.: Evaluation of GOME satellite measurements of tropospheric $\mathrm{NO}_{2}$ and $\mathrm{HCHO}$ using regional data from aircraft campaigns in the southeastern United States, J. Geophys. Res., 109, D24307, doi:10.1029/2004JD004869, 2004.

Massons, J., Domingo, D., and Lorente, J.: Seasonal cycle of cloud cover analyzed using Meteosat images, Ann. Geophys., 16, 331341, 1998,

http://www.ann-geophys.net/16/331/1998/.

Meerkötter, R., König, C., Bissolli, P., Gesell, G., and Mannstein, H., A 14-year European Cloud Climatology from NOAA/AVHRR data in comparison to surface observations, Geophys. Res. Lett., 31, 15 103, doi:10.1029/2004GL020098, 2004.

Meirink, J. F., Eskes, H. J., and Goede, A. P. H.: Sensitivity analysis of methane emissions derived from SCIAMACHY observations through inverse modelling, Atmos. Chem. Phys., 5, 9405-9445, 2005, http://www.atmos-chem-phys.net/5/9405/2005/.

Richter, A. and Burrows, J. P.: Tropospheric $\mathrm{NO}_{2}$ from GOME measurements, Adv, Space Res., 29, 1673-1683, 2002.

Richter, A., Burrows, J. P., Nusz, H., Granier, C., and Niemeier, U.: Increase in tropospheric nitrogen dioxide over China observed from space, Nature, 437, 129-132, 2005.

Thomas, S. M., Heidinger, A. K., and Pavolonis, M. J., Comparison of NOAA's Operational AVHRR-Derived Cloud Amount to Other Satellite-Derived Cloud Climatologies., J. Climate, 17, 4805-4822, 2004

Tjemkes, S., Lutz, H., Duff, C., Stuhlmann, R., and McNally, A.: Detection of cloud-free areas as a function of Sensor Resolution and Time Sampling, Technical Memorandum No. 10, 2003.

Wielicki, B. A. and Parker, L.: On the determination of cloud cover from satellite sensors: The effect of sensor spatial resolution, J. Geophys. Res., 97, 12 799-12 823, 1992. 